\begin{tabular}{l|l|l} 
Jelume 6 \\
\hline Istarnal Kependidikan Dasar & $\begin{array}{l}\text { Volum } \\
\text { Nomor 1 } \\
\text { Tahun 2021 }\end{array}$ \\
\hline
\end{tabular}

\title{
Analisis Kualitas Butir Soal Ulangan Harian di Sekolah Dasar dengan Model Rasch
}

\author{
Anis Fauziana', Andhita Dessy Wulansari ${ }^{2}$ \\ 1SDN Klakahrejo I/578, 2IAIN Ponorogo \\ nis.girls02@gmail.com, andhita@iainponorogo.ac.id
}

\begin{abstract}
Abstrak
Analisis butir soal dapat digunakan untuk membantu meningkatkan kualitas butir soal melalui revisi atau membuang soal yang tidak efektif, dan dapat digunakan sebagai informasi diagnostik pada siswa, apakah mereka sudah memahami materi yang telah diajarkan. Pada karya ilmiah ini, peneliti akan melakukan analisis butir soal ulangan harian menggunakan model Rasch yang melibatkan satu parameter untuk mengukur tingkat kesulitan soal pada materi lingkaran kelas VI di SDN Klakahrejo I/578. Tujuan penelitian ini adalah untuk mengetahui bagaimana kualitas butir soal dan kemampuan siswa sekolah dasar, khususnya SDN Klakahrejo I/578. Penelitian ini merupakan penelitian evaluatif dengan pendekatan deskriptif kuantitatif. Hasil penelitian menunjukkan bahwa semua soal yang diujikan pada peserta tes adalah valid dan reliabilitas. Hasil Tingkat kesukaran dari 10 soal yang diuji adalah 4 soal tergolong mudah, 4 soal tergolong sedang dan 2 soal tergolong sangat sukar. Berdasarkan penelitian yang telah dilakukan dapat juga diketahui bahwa nilai estimasi kemampuan orang dari 31 siswa bervariasi pada rentang -0.69 sampai dengan 3,05. Hal ini menunjukkan kemampuan siswa tergolong sedang sampai sangat tinggi.
\end{abstract}

Kata Kunci: valid, reliabilitas, analisis butir soal model Rasch

\begin{abstract}
Item analysis can be used to help improve the quality of items through revision or discarding ineffective questions, and can be used as diagnostic information for students, whether they have understood the material that has been taught. In this scientific paper, the researcher will analyze the daily test items using the Rasch model which involves one parameter to measure the level of difficulty of the questions in the class VI circle material at SDN Klakahrejo I/578. The purpose of this study was to determine the quality of the items and the ability of elementary school students, especially SDN Klakahrejo I/578. This research is an evaluative research with a quantitative descriptive approach. The results showed that all the questions tested on the test takers were valid and reliable. Results The difficulty level of the 10 questions tested was 4 questions classified as easy, 4 questions classified as moderate and 2 questions classified as very difficult. Based on the research that has been done, it can also be seen that the estimated value of the ability of the 31 students varies in the range of -0.69 to 3.05. This shows that students' abilities are classified as moderate to very high.
\end{abstract}

Keywords : valid, reliability, item analysis of the Rasch model 


\section{A. PENDAHULUAN}

Pendidikan merupakan kunci utama kemajuan bangsa, dan upaya peningkatan kualitas pendidikan harus terus dilakukan agar Indonesia mampu bersaing di era globalisasi. Peran pendidik dan proses pembelajaran adalah bagian yang penting dalam menentukan kualitas pendidikan. Peran pendidik tidak hanya terbatas dalam merancang dan melaksanakan pembelajaran, melainkan juga dalam melakukan assesmen proses dan hasil belajar.

Russel \& Airasian mengemukakan bahwa assesmen merupakan komponen penting dalam pembelajaran. ${ }^{1}$ Assesmen memerlukan suatu alat untuk mengukur kemampuan siswa. Salah satu alat yang digunakan adalah tes, agar tes yang dilakukan dapat mengetahui kemampuan siswa yang sebenarnya, maka diperlukan suatu perangkat tes. Perangkat tes yang baik memiliki tiga kriteria, yaitu; isi teks sesuai dengan materi yang hendak diujikan (validitas isi), teks memiliki konstruk yang baik (validitas konstruk), dan memiliki keajegan (realibilitas). Tes dikatakan reliabel jika digunakan untuk mengukur beberapa kali, baik pada peserta yang sama atau berbeda, hasilnya relatif sama. ${ }^{2}$

Pada kenyataannya, banyak perangkat tes masih belum diketahui kualitas soalnya, sehingga terjadi penilaian semu yang berdampak tidak terukurnya kemampuan siswa yang sebenarnya. Hal ini dapat disebabkan oleh rendahnya kemampuan guru dalam mengevaluasi dan menyusun perangkat tes sebagai sarana untuk mengevaluasi. Evaluasi disini berfungsi untuk mengetahui tercapai atau tidaknya tujuan pembelajaran dan mengetahui sejauh mana kualitas butir soal yang disusun.

Analisis butir soal membantu meningkatkan kualitas butir soal melalui revisi atau membuang soal yang tidak efektif, selain itu dapat digunakan sebagai informasi diagnostik pada siswa, apakah mereka sudah memahami materi yang telah diajarkan. Retnawati menyebutkan bahwa analisis butir soal dalam pendidikan dapat dilakukan melalui dua pendekatan yaitu pendekatan klasik dan modern. Analisis butir soal secara klasik adalah proses penelaahan butir soal melalui informasi dari jawaban peserta didik guna meningkatkan mutu butir soal yang bersangkutan dengan menggunakan teori tes Klasik. $^{3}$ Selanjutnya analisis butir soal secara modern adalah penelaahan butir soal dengan menggunakan Item Respon Theory (IRT) atau teori jawaban butir soal. Item Respon Theory merupakan suatu teori yang menggunakan fungsi matematika untuk menghubungkan antara peluang menjawab benar suatu soal dengan kemampuan siswa.

\footnotetext{
1 Sri Sumarnia, "Designing Ict Competences-Integrated Assessment Instruments Of Practical Key Teaching Competences For English Language Education Study Program," Ijlecr-International Journal Of Language Education And Culture Review 5, no. 1 (2019): 47-55.

2 Heri Retnawati, “Teori Respons Butir Dan Penerapannya: Untuk Peneliti, Praktisi Pengukuran Dan Pengujian, Mahasiswaa Pascasarjana," Yogyakarta: Nuha Medika, 2014.

${ }^{3}$ Heri Retnawati, “Validitas Reliabilitas Dan Karakteristik Butir,” Yogyakarta: Parama Publishing, 2016.
} 
Georg Rasch mengembangkan satu model analisis dari teori respon butir (Item Response Theory, IRT) disebut model Rasch atau 1PL (satu parameter logistik). ${ }^{4}$

Hasil penelitian Fitri Alfarisa and Dian Normalitasari Purnama, menunjukkan bahwa analisis menggunakan pemodelan Rasch dapat menjelaskan kualitas butir soal ${ }^{5}$ senada dengan hasil penelitian Tyas, Hamdu dan Pranata yang menyebutkan, bahwa dengan analisis butir soal model Rasch dapat menjelaskan kualitas suatu soal pilihan ganda dan kemampuan siswa dalam mengurutkan bilangan pecahan siswa sekolah dasar. ${ }^{6}$ Hasil penelitian yang dilakukan oleh Anita Sulis Tyowati dan Zuldafrial juga menjelaskan bahwa analisis butir menggunakan model Rasch dapat memberikan informasi tingkat abilitas siswa dan tingkat kesulitan soal, ${ }^{7}$ bahkan Dwinata menyebutkan, bahwa analisis butir soal menggunakan model Rasch mampu menunjukkan kemampuan siswa dalam memecahkan suatu masalah. ${ }^{8}$

Analisis butir soal dalam pembelajaran matematika sangat berguna bagi guru. Hal ini dikarenakan matematika merupakan mata pelajaran yang dianggap sulit bagi sebagian besar siswa sekolah dasar. ${ }^{9}$ Analisis yang dilakukan akan dapat membantu guru menemukan kesulitan-kesulitan yang dialami siswa dalam belajar matematika. Suwarsito \& Sutomo menyebutkan, bahwa banyak guru sekolah dasar yang belum melakukan analisis butir soal. Hal ini dikarenakan salah satu penyebabnya adalah perhitungan yang terlalu banyak jika melakukan melakukan analisis secara manual dan beberapa guru khawatir akan kebocoran soal yang mereka buat. Alasan inilah yang membuat kualitas soal yang diberikan pada siswa masih rendah. ${ }^{10}$

Berdasarkan hasil wawancara peneliti pada 21 guru SDN Klakahrejo I/578 menunjukkan bahwa 30\% guru di sekolah tersebut belum melakukan analisis butir soal dan sisanya sudahmelakukan analisis butir soal tetapi belum dikembangkan untuk mengetahui tingkat kesukaran soal. Berdasarkan hasil wawancara tersebut maka peneliti merasa perlu untuk mengetahui bagaimana kualitas butir soal dan kemampuan siswa sekolah dasar, khususnya Sekolah Dasar Negeri (SDN) Klakahrejo I/ 578.

\footnotetext{
4 Retnawati, “Teori Respons Butir Dan Penerapannya: Untuk Peneliti, Praktisi Pengukuran Dan Pengujian, Mahasiswa Pascasarjana."

5 Fitri Alfarisa and Dian Normalitasari Purnama, "Analisis Butir Soal Ulangan Akhir Semester Mata Pelajaran Ekonomi SMA Menggunakan RASCH Model," Jurnal Pendidikan Ekonomi Undiksha 11, no. 2 (2019): 366-74.

6 Tyas, Hamdu, and Pranata.

${ }^{7}$ Anita Anita, Sulis Tyowati, and Zuldafrial Zuldafrial, “Analisis Kualitas Butir Soal Fisika Kelas X Sekolah Menengah Atas,” Edukasi: Jurnal Pendidikan 16, no. 1 (2018): 35-47.

8 Alona Dwinata, “Analisis Kemampuan Pemecahan Masalah Menggunakan Pemodelan RASCH Pada Materi Permutasi Dan Kombinasi," in PRISMA, Prosiding Seminar Nasional Matematika, vol. 2, 2019, $124-31$.

9 Nita Syahputri, "Rancang Bangun Media Pembelajaran Matematika Sekolah Dasar Kelas 1 Menggunakan Metode Demonstrasi," Jurnal Sistem Informasi Kaputama 2, no. 1 (2018).

${ }^{10}$ Hindayati Mustafidah and Harjono Harjono, "Implementasi Program QUEST Untuk Menganalisis Butir Soal Bagi Guru-Guru SMP Muhammadiyah 2 Karanglewas," JPPM (Jurnal Pengabdian Dan Pemberdayaan Masyarakat) 3, no. 2 (2019): 321-28.
} 
Berdasarkan latar belakang penelitian tersebut, maka tujuan dalam penelitian ini adalah mengetahui kualitas soal ulangan harian dilihat dari segi validitas, reliabilitas, dan tingkat kesukaran serta sebaran kemampuan matematika siswa.

\section{B. METODE PENELITIAN}

Penelitian yang dilakukan berupa penelitian evaluasi. Penelitian ini menggunakan metode deskriptif kuantitatif untuk menganalisis indeks tingkat kesulitan, validitas dan reliabilitas dari butir soal yang diujikan serta tingkat kemampuan siswa. Kegiatan penelitian ini dilaksanakan di kelas VI (enam) SDN Klakahrejo I/ 578 yang beralamat di Jalan Klakahrejo Sekolahan II/ 6 Kecamatan Benowo Kota Surabaya. Subyek penelitian pada penelitian ini adalah siswa kelas VI (enam) yang berjumlah 31 siswa dengan 12 siswa perempuan dan 19 siswa laki-laki yang berasal dari wilayah sekitar Klakahrejo dan sekitarnya. Instrumen yang digunakan pada penelitian ini adalah Lembar Telaah Butir Soal bentuk pilihan ganda yang diadaptasi dari Nurgiyantoro. ${ }^{11}$ Validitas isi soal ulangan harian yang diberikan pada siswa dalam penelitian ini diukur menggunakan rumus Lawshe ${ }^{12}$.

$$
C V R=\frac{\left[n_{e}-\left(\frac{N}{2}\right)\right]}{\left(\frac{N}{2}\right)}
$$

Selanjutnya uji reliabilitas menggunakan rumus Alpha Cronbach. Menurut Muhidin dan Abdurrahman, rumus Alpha digunakan untuk mencari reliabilitas yaitu: ${ }^{13}$

$$
r_{11}=\left(\frac{k}{k-1}\right)\left(1-\frac{\sum_{i=1}^{n} \sigma_{i}^{2}}{\sigma_{t}^{2}}\right)
$$

Sedangkan rumus untuk varians, yakni:

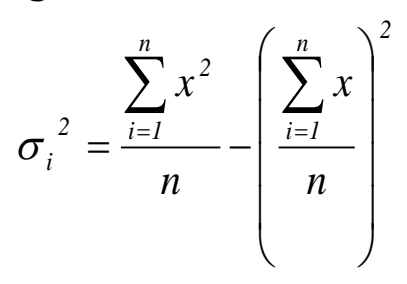

${ }^{11}$ Hari Wahyono, "Penilaian Kemampuan Berbicara Di Paerguruan Tinggi Berbasis Teknologi Informasi Wujud Aktualisasi Prinsip-Prinsip Penilaian," Transformatika: Jurnal Bahasa, Sastra, Dan Pengajarannya 1, no. 1 (2017): 19-34. (1975)

${ }^{12}$ C. H. P. p. Lawshe, “A Quantitative Approach to Content Validity 1,” Personnel Psychology Vol. 28 No

13 Sambas Ali Muhidin and Maman Abdurahman, "Analisis Korelasi, Regresi, Dan Jalur Dalam Penelitian," Bandung: Pustaka aSetia 30 (2007). 
Tingkat kesulitan diukur menggunakan model Rasch sebagai berikut: ${ }^{14}$

$$
P_{i}(\theta)=\frac{e^{\left(\theta-b_{i}\right)}}{1+e^{\left(\theta-b_{i}\right)}}
$$

Pengukuran indeks tingkat kesukaran dilakukan dengan menggunakan program Quest.

\section{HASIL DAN PEMBAHASAN}

Jumlah dari butir soal yang diteliti adalah 10 soal. Bentuk soal yang diujikan adalah soal pilihan ganda. Soal yang diujikan adalah soal matematika ulangan harian kelas VI. Peserta tes adalah siswa kelas VI yang berjumlah 31 siswa. Hasil penelitian mendeskripsikan kualitas soal ditinjau dari validitas, reliabilitas dan tingkat kesukaran soal menurut model Rasch. Validitas yang diukur dalam penelitian ini berupa validitas isi. Pengukuran validitas isi menggunakan metode CVR. Penelitian ini melibatkan 7 orang sebagai rater dengan memilih 3 pilihan jawaban yaitu: diterima, diterima dengan review dan ditolak. Berikut hasil telaah 7 orang rater untuk soal nomor 1 pada tabel 1 berikut.

Tabel 1. Hasil analisis butir soal nomor 1

\begin{tabular}{|c|c|}
\hline RATER & PENILAIAN \\
\hline Rater 1 & DITERIMA \\
\hline Rater 2 & DITERIMA \\
\hline Rater 3 & DITERIMA \\
\hline Rater 4 & DITERIMA \\
\hline Rater 5 & DITERIMA \\
\hline Rater 6 & DITERIMA \\
\hline Rater 7 & DITERIMA \\
\hline
\end{tabular}

Dari 7 orang rater, 7 orang menyatakan soal no 1 diterima, dan tidak rater yang menyatakan diterima dengan review dan ditolak. Dari data tersebut dapat dihitung dengan koefisien/indeks CVR sebagai berikut:

$C V R=\frac{\left[n_{e}-\left(\frac{N}{2}\right)\right]}{\left(\frac{N}{2}\right)}$
$C V R=\frac{\left[7-\left(\frac{7}{2}\right)\right]}{\left(\frac{7}{2}\right)}$

$C V R=1$

14 Retnawati, "Teori Respons Butir Dan Penerapannya: Untuk Peneliti, Praktisi Pengukuran Dan Pengujian, Mahasiswa Pascasarjana." 
Arti nilai CVR positif adalah bahwa setidaknya setengah rater menilai soal ini diterima (penting/essensial). Semakin tinggi nilai CVR (positif) maka semakin penting dan semakin tinggi validitas isinya. Koefisien/indeks CVR yang diperoleh diatas (1) lebih besar jika dibandingkan dengan skor minimal (minimum value) CVR sehingga menunjukkan bahwa soal nomor 1 yang digunakan sudah memenuhi validitas isi yang baik (valid). Dengan cara yang sama diperoleh hasil analisis pada tabel 2 sebagai berikut.

Tabel 2. Hasil analisis butir soal nomor 2-10

\begin{tabular}{|c|c|}
\hline NO. SOAL & HASIL ANALISIS \\
\hline 2 & VALID \\
\hline 3 & VALID \\
\hline 4 & VALID \\
\hline 5 & VALID \\
\hline 6 & VALID \\
\hline 7 & VALID \\
\hline 8 & VALID \\
\hline 9 & VALID \\
\hline 10 & VALID \\
\hline
\end{tabular}

Kualitas soal ditinjau dari reliabilitas dihitung menggunakan Alpha Cronbach pada tabel 3 sebagai berikut.

Tabel 3. Koefisien Reliabilitas

Reliability Statistics

\begin{tabular}{|c|c} 
Cronbach's Alpha & Nof Items \\
\hline, 5 & 10
\end{tabular}

Hasil realibilitas alpha cronbach untuk soal ulangan harian kelas VI menunjukkan angka 0,5. Hal ini berarti soal ulangan harian kelas VI memiliki reliabilitas sedang.

Sebelum menganalisis kualitas soal berdasarkan tingkat kesukaran, peneliti telah melakukan analisis keccocokan dan kelolosan sebagai prasyarat. Hasil analisis tersebut terlihat pada tabel 4 sebagai berikut: (Nilai infit mnsq yang diterima berkisar $0,77-1,33)$.

Tabel 4. Hasil Uji Kecocokan Model Rasch

\begin{tabular}{|c|c|c|c|}
\hline Nomor Soal & Infit Mnsq & Cocok & Tidak Cocok \\
\hline 1 & 0,95 & $\sqrt{ }$ & \\
\hline 2 & 0,79 & $\sqrt{ }$ & \\
\hline 3 & 0,78 & $\sqrt{ }$ & \\
\hline 4 & 1,10 & $\sqrt{ }$ & \\
\hline 5 & 1,70 & & $\sqrt{ }$ \\
\hline 6 & 1,06 & $\sqrt{ }$ & \\
\hline 7 & 1,07 & $\sqrt{ }$ & \\
\hline 8 & 0,83 & $\sqrt{ }$ & \\
\hline 9 & 0,71 & $\sqrt{ }$ & \\
\hline 10 & 0,79 & $\sqrt{ }$ & \\
\hline
\end{tabular}


Berdasarkan Tabel 4 diperoleh bahwa dari 10 soal yang diujikan ternyata satu soal yang tidak cocok dengan model Rasch yaitu soal nomor 5. Selanjutnya akan disajikan tabel kelolosan butir soal ulangan harian kelas VI sebagai berikut: (nilai outfit t yang diterima berkisar antara -2,00 sampai 2,00).

Selanjutnya akan disajikan tabel kelolosan butir soal ulangan harian kelas VI pada tabel 5 sebagai berikut:

Tabel 5. Hasil Uji Kelolosan Model Rasch

\begin{tabular}{|c|c|c|c|}
\hline Nomor Soal & Outfit t & Lolos & Tidak Lolos \\
\hline 1 & $-0,2$ & $\sqrt{ }$ & \\
\hline 2 & $-0,3$ & $\sqrt{ }$ & \\
\hline 3 & $-0,5$ & $\sqrt{ }$ & \\
\hline 4 & 1,9 & $\sqrt{ }$ & \\
\hline 5 & 2,7 & & $\sqrt{ }$ \\
\hline 6 & $-0,1$ & $\sqrt{ }$ & \\
\hline 7 & 0,1 & $\sqrt{ }$ & \\
\hline 8 & $-0,5$ & $\sqrt{ }$ & \\
\hline 9 & -1 & $\sqrt{ }$ & \\
\hline 10 & $-0,9$ & solnom & \\
\hline
\end{tabular}

Sesuai tabel di atas, ada satu soal yang tidak lolos yaitu soal nomor 5 . Artinya soal nomor 5 akan lebih cocok jika dianalisis dengan menggunakan logistik 2 parameter atau 3 parameter yang juga melibatkan parameter daya beda (b) dan parameter tebakan semu.

Tingkat kesukaran diketahui berdasarkan nilai delta (nilai b/nilai Thresholds). Berikut ini akan dijabarkan nilai Thresholds (nilai b) pada soal ulangan harian kelas VI pada tabel 6.

Tabel 6. Nilai Thresholds Pada Soal Ulangan Harian

\begin{tabular}{|c|c|c|c|c|c|c|}
\hline \multirow{2}{*}{ No Soal } & \multirow{2}{*}{$\begin{array}{c}\text { Nilai Thresholds } \\
\text { (nilai b) }\end{array}$} & $\begin{array}{c}\text { Sangat } \\
\text { mudah }\end{array}$ & Mudah & Sedang & Sukar & $\begin{array}{c}\text { Sangat } \\
\text { sukar }\end{array}$ \\
\hline & $-1,32$ & & $\sqrt{ }$ & & & \\
\hline 2 & $-1,76$ & & $\sqrt{ }$ & & & \\
\hline 3 & $-1,32$ & & $\sqrt{ }$ & & & \\
\hline 4 & $-0,99$ & & & $\sqrt{ }$ & & \\
\hline 5 & 0,34 & & & $\sqrt{ }$ & & \\
\hline 6 & $-1,32$ & & $\sqrt{ }$ & & & \\
\hline 7 & 0,69 & & & $\sqrt{ }$ & \\
\hline 8 & 2,30 & & & & & $\sqrt{ }$ \\
\hline 9 & 2,51 & & & & $\sqrt{ }$ & $\sqrt{ }$ \\
\hline 10 & 0,87 & & & & & \\
\hline
\end{tabular}

Tabel di atas menunjukkan bahwa dari 10 soal ulangan harian terdapat 4 soal berkategori mudah (soal nomor 1,2,3,6), 4 soal berkategori sedang (soal nomor 4, 5, 7,10 ) dan 2 soal berkategori sangat sukar (soal nomor 8 dan 9). Artinya distribusi (penyebaran) tingkat kesulitan sudah seimbang. Dilihat dari banyaknya siswa yang mampu menjawab benar dan salah pada soal tersebut diperoleh bahwa soal yang sedang 
dan sukar lebih banyak dari soal yang mudah sehingga tingkat kesukaran dikatakan baik..$^{15}$ (Widyastuti \& Mardiyah, 2016).

Berdasarkan uraian di atas, soal ulangan harian kelas 6 materi lingkaran di SDN Klakahrejo I/578 memiliki kevalidan 100\% karena semua soal vaild memiliki reliabilitas sedang dan tingkat kesukaran yang baik, dengan demikian kualitas soal ulangan harian tersebut tergolong baik (Nugraha, 2019; Widyastuti \& Mardiyah, 2016). Butir soal dikatakan memiliki kualitas yang baik, apabila soal tersebut memiliki validitas tes termasuk kategori valid. Reliabilitas minimal sedanng dan kesukaran tes termasuk kategori minimal sedang.

Tingkat kemampuan siswa diketahui berdasarkan nilai estimate(theta/ $\theta$ ). Kriteria pada analisis kemampuan siswa tersaji pada tabel 7 berikut ini.

Tabel 7. Kriteria Nilai EstimasiTheta

\begin{tabular}{|c|c|}
\hline Nilai EstimasiTheta & Keterangan \\
\hline$\theta>2$ & Sangat tinggi \\
\hline $1<\theta \leq 2$ & Tinggi \\
\hline$-1<\theta \leq 1$ & Sedang \\
\hline$-1>\theta \geq-2$ & Rendah \\
\hline$\theta<-2$ & Sangat Rendah \\
\hline
\end{tabular}

Hasil analisis dari nilai estimasi theta yang diperoleh oleh 31 siswa menunjukkan bahwa kemampuan siswa kelas VI yang terdiri dari 31 siswa bervariasi yaitu berkisar antara 0.67 sampai 4,00. Hal ini menunjukkan bahawa kemampuan siswa kelas VI di SDN Klakahrejo I/578 tergolong sedang sampai tinggi.

\section{PENUTUP}

\section{Simpulan}

Berdasarkan deskripsi hasil penelitian evaluatif dan pembahasan yang telah diuraikan pada bab sebelumnya, maka dapat ditarik kesimpulan bahwa semua soal ulangan harian kelas VI materi lingkaran semua dinyatakan valid, reliabilitas soal tergolong sedang dan berdasarkan analisis butir soal menggunakan model Rasch diperoleh bahwa pada soal ulangan harian kelas VI terdapat 4 soal berkategori mudah (soal nomor 1,2,3,6), 4 soal berkategori sedang (soal nomor 4,5, 7,10) dan 2 soal berkategori sangat sukar (soal nomor 8 dan 9) serta kemampuan siswa kelas VI SDN Klakahrejo I tergolong sedang sampai tinggi dengan rentang berkisar antara -0,65 sampai 3,05.

\section{Saran}

Berdasarkan pengalaman peneliti, peneliti juga dapat menganalisis butir soal menggunakan lebih banyak parameter agar ketepatan dalam analisis butir soal dapat lebih baik dan diketahui kesalahan, kekurangan, dan ketidaksempurnaan dari item soal

${ }^{15}$ I. Widyastuti and S. U. K. Mardiyah, "Kualitas Butir Soal Ujian Akhir Semester Gasal Standar Kompetensi Mengelola Sistem Kearsipan Kelas Xi Administrasi Perkantoran Di Smk Negeri 1 Yogyakarta Tahun Ajaran 2015/2016," Jurnal Pendidikan Administrasi Perkantoran-S1 Vol. 5 No. (2016). 
yang diujikan. Penelitian selanjutnya diharapkan dapat menganalisis butir soal dengan beragam parameter sehingga kualitas item soal yang duijkan semakin baik misalnya dengan melakukan analisis IRT selain model Rasch seperti model logistik 2 parameter atau 3 parameter.

\section{E. DAFTAR PUSTAKA}

Alfarisa, Fitri, and Dian Normalitasari Purnama. "Analisis Butir Soal Ulangan Akhir Semester Mata Pelajaran Ekonomi SMA Menggunakan RASCH Model." Jurnal Pendidikan Ekonomi Undiksha 11, no. 2 (2019): 366-74.

Anita, Anita, Sulis Tyowati, and Zuldafrial Zuldafrial. "Analisis Kualitas Butir Soal Fisika Kelas X Sekolah Menengah Atas.” Edukasi: Jurnal Pendidikan 16, no. 1 (2018): 3547.

Dwinata, Alona. "Analisis Kemampuan Pemecahan Masalah Menggunakan Pemodelan RASCH Pada Materi Permutasi Dan Kombinasi." In PRISMA, Prosiding Seminar Nasional Matematika, 2:124-31, 2019.

Lawshe, C. H. P. p. "A Quantitative Approach to Content Validity 1." Personnel Psychology Vol. 28 No (1975).

Muhidin, Sambas Ali, and Maman Abdurahman. "Analisis Korelasi, Regresi, Dan Jalur Dalam Penelitian." Bandung: Pustaka Setia 30 (2007).

Mustafidah, Hindayati, and Harjono Harjono. "Implementasi Program QUEST Untuk Menganalisis Butir Soal Bagi Guru-Guru SMP Muhammadiyah 2 Karanglewas." JPPM (Jurnal Pengabdian Dan Pemberdayaan Masyarakat) 3, no. 2 (2019): 321-28.

Retnawati, Heri. "Teori Respons Butir Dan Penerapannya: Untuk Peneliti, Praktisi Pengukuran Dan Pengujian, Mahasiswa Pascasarjana.” Yogyakarta: Nuha Medika, 2014.

___. "Validitas Reliabilitas Dan Karakteristik Butir." Yogyakarta: Parama Publishing, 2016.

Sumarni, Sri. "designing ict competences-integrated assessment instruments of practical key teaching competences for english language education study program." Ijlecr-international journal of language education and culture review 5, no. 1 (2019): 4755.

Syahputri, Nita. "Rancang Bangun Media Pembelajaran Matematika Sekolah Dasar Kelas 1 Menggunakan Metode Demonstrasi." Jurnal Sistem Informasi Kaputama 2, no. 1 (2018).

Tyas, Efty Hatining, Ghullam Hamdu, and Oyon Haki Pranata. "Analisis Soal Pilihan Ganda Dengan Menggunakan Pemodelan RASCH Untuk Mengukur Kemampuan Siswa Dalam Mengurutkan Bilangan Pecahan Di Sekolah Dasar." PEDADIDAKTIKA: Jurnal Ilmiah Pendidikan Guru Sekolah Dasar 7, no. 2 (2020): 1-12.

Wahyono, Hari. "Penilaian Kemampuan Berbicara Di Perguruan Tinggi Berbasis Teknologi Informasi Wujud Aktualisasi Prinsip-Prinsip Penilaian." Transformatika: Jurnal Bahasa, Sastra, Dan Pengajarannya 1, no. 1 (2017): 19-34.

Widyastuti, I., and S. U. K. Mardiyah. "Kualitas Butir Soal Ujian Akhir Semester Gasal Standar Kompetensi Mengelola Sistem Kearsipan Kelas Xi Administrasi Perkantoran Di Smk Negeri 1 Yogyakarta Tahun Ajaran 2015/2016." Jurnal Pendidikan Administrasi Perkantoran-S1 Vol. 5 No. (2016). 
Analisis Kualitas Butir | 19 